\title{
Disability, family and society: new thinking of an old debate
}

\author{
Deficiência, família e sociedade: \\ novas formas de pensar sobre um velho debate
}

Edward Goldson ${ }^{1}$

\begin{abstract}
The debate about disability, family and society is an old one. The needs of individuals with disabilities have not been a priority in most societies. However, this population is increasing with the advances in our medical technology and we can no longer ignore them. Overall care, from diagnosis to treatment and integration into society has been fragmented and disorganized. Thus, new thinking about individuals with disabilities has to take place. This article suggests the need for a paradigm shift has to how individuals with disabilities should be viewed and suggests a different model for the development of systems to meet the needs of this growing population.
\end{abstract}

Key words Disability, Handicap, Paradigm shift, Family, Society
Resumo O debate sobre a deficiência, a família e a sociedade é antigo. As necessidades das pessoas com deficiência não têm sido uma prioridade na maioria das sociedades. No entanto, esta população está crescendo com os avanços da nossa tecnologia médica e não podemos mais ignorá-la. Cuidados gerais, do diagnóstico ao tratamento $e$ a integração na sociedade tem sido fragmentada e desorganizada. Assim, uma nova forma de pensar a respeito de pessoas com deficiência precisa ser elaborada. Este artigo sugere a necessidade de uma mudança de paradigma em como os indivíduos com deficiência devem ser vistos e sugere um modelo diferente para o desenvolvimento de sistemas para atender as necessidades desta população crescente.

Palavras-chave Deficiência, Incapacidade, Mudança de paradigma, Família, Sociedade
${ }^{1}$ Children's Hospital Colorado, University of Colorado Medical School. 13123 East $16^{\text {th }}$ Avenue. 80045 Aurora CO USA. Edward.Goldson@ childrenscolorado.org 


\section{Introduction}

The articles included in this thematic edition of the journal cover a large spectrum of topics ranging from concerns about athletes with disabilities, to the social structure and economic circumstances under which individuals with disabilities (IwDs) exist within Brazilian society. Issues about inclusion of the individual with a disability in the life of the country, supports for their education and well-being, protection of the disabled, attitudes toward individuals with a developmental disability and family functioning are among the papers included in this issue. The question than raised for this is whether among the individual papers is there a dominant theme or basic issue(s) that stands out and should be highlighted. The two themes that seem to emerge from this collection of articles are: 1) How do we define disability and what are the attitudes, myths, expectations and roles for individuals with disabilities and, 2) What is the societal response to these attitudes and perceptions and how do we meet the needs of IwDs who may number well over $10 \%$ of the population.

If we look at the trajectory of disability one recognizes there are genetic, molecular, anatomic, prenatal and postnatal factors that contribute to the loss or compromise of physical and/or intellectual function. As a result an individual emerges with characteristics or compromises in her or his ability to function as effectively in the community as someone we would consider "able bodied." Such individuals are somewhat different from the rest of the community. As human beings we often feel uncomfortable with groups who are different from the rest of us and this seems to be true of IwDs. We may ask, "why are they like this?" What caused this? How do I engage them? Are they contagious? Are they bad, and so on? From an intervention or treatment perspective, we now have many ways of supporting such individuals with technological advances such as artificial limbs, augmentative communication systems, computer programs, physical and occupational therapies, educational strategies and community and family supports. Many of these advances and interventions have been shown to improve the lives of individuals with disabilities. However, there remain significant problems for IwDs. If we consider individuals with disability the term handicap inevitably emerges and disability equals or is the same as handicap. This is a conceptual problem and generates much confusion, misinformation and influences behavior towards IwDs. I would suggest that the construct of handicap has had a negative effect on how we perceive people with disabilities. It is important and must be recognized that handicap is not a biological construct, which is the case for disability, but rather a social construct. Individuals may have a disability but need not be handicapped. Society creates handicap and all of the consequences of such a categorization upon how we judge and accept people. Least acceptable to us are those with intellectual disabilities, neurological problems, behavioral problems, genetic syndromes, physical deformities and generally those who require the most supports. The most acceptable disability is among those individuals who are more like us and with whom we can easily identify and communicate; those with an orthopedic problem, a chronic illness but who are intellectually intact.

Among the consequences of these perceptions is a "sociologic destiny" articulated by Resnick in 1984, which I believe still holds in 2016. This destiny includes lower educational attainment, more non-employment, lower wages when individuals are employed, a lack of upward mobility, poverty, social isolation, more medical problems; more care. In a word, they cost us more and we feel they contribute less to the community. Society often views the disabled (handicapped) as "less than human." There is the perception they do not feel pain the way typical individuals. They do not have the same needs, desires, or feelings as typical individuals and therefore are not entitled to the same rights and considerations as typical individuals. As a result, the disabled child or adult is depersonalized and isolated and the family often demonized and marginalized. Finally, the individual is often viewed as an "object" which may be treated with impunity and even exploited. Thus, what is a biological deficit or challenge becomes a negative social construct.

To be a helped person in this culture, which values self-reliance and independence, includes subtle yet pervasive expectations in terms of dependency and gratitude. The ramifications of such a social identify are enormous ${ }^{1}$.

The vulnerability of disabled children stems from their experience of having disabilities in a society which puts value on being nondisabled ('able bodied') and which discriminates which discriminates against disabled people ${ }^{2}$.

If we consider the current perceptions of IwDs to be untrue and destructive we need to combat these views. There must be a commitment on the part of all involved in the lives of those with a disability - politicians, government 
ministers, government agencies, social and medical services, the education sector and the families - to vigorously seek to change these perceptions. Families are particularly critical as it becomes essential they build strong collaborations within the various developmental disabilities group and stand together for the advocacy of their disabled family members. As societies we need to be committed to supporting the well-being of those with disabilities and confront the myths and disinformation at multiple levels. Our discomfort with disability grows out of ignorance and anxiety with what is unfamiliar and different. Thus, change needs to be effected in the population in general as well as among those who care for these individuals; teachers, health care providers, politicians and other members of society.

In order to combat these misperceptions we need to know from where these ideas originate, which is how one would need to approach any form of prejudice. A commitment to support investigations trying to understand the underpinnings of prejudice against individuals with disabilities must be put in place at the highest level of government. Once meaningful data are gathered one could proceed to initiate an intensive educational effort, starting very early in life, to alter the community's and society's negative view of IwDs. As part of this process, all need to appreciate that individuals with disabilities are more than a check list of "deficits." They need to be seen as human beings who have the capability to contribute to the community, although they will require more supports to accomplish that goal. In a word, there must be a paradigm shift in society's perception of individuals with disabilities. Medical and sociologic paradigm shifts take time. Nevertheless, while one works to accomplish those shifts one can put into place the structures enabling those shifts to be operationalized; laws, development of curricula, creation of environments suitable for individuals with disabilities, technological supports etc.

One can draw an interesting parallel as to how perspective can alter perception and intervention from the history of autism ${ }^{3}$. Both Kanner and Asperger described somewhat similar groups of children with major developmental challenges rendering many of them with disabilities. Asperger, rather than wanting to "cure" these children, sought to identify and celebrate what skills they had and to help them find their place in the world as happy, productive human beings. He did not see these individuals as "patients" but as potential bakers, barbers, musicians, academics and engineers, etc. Kanner, on the other hand saw these young patients as being terribly ill and a drain on their parents and society. Unfortunately, much of his thinking led to inappropriate and cruel "treatments" that resulted in much pain and suffering for these young people and their families. In addition, it contributed to the perception that people meeting the criteria for autism were "damaged." I would suggest as we encounter and work with individuals with disabilities that we actively adopt Asperger's view, rather than the one Kanner supported.

The question that than emerges, as we make the paradigm shift, is how can one go about creating an environment that acknowledges diversity and uniqueness? As noted above, a comprehensive universal education program would have to be created and funded. The next issue is how can this be operationalized? Let us consider a model that we will call a "dream sheet" (the ideal) that will be established in the context of a "medical home." A medical home is defined as primary care that is accessible, continuous, comprehensive, family-centered, coordinated, compassionate, and culturally effective ${ }^{4}$. In a medical home a physician and associates work in partnership with the family/patient to assure that all of the patient's medical and non-medical needs are met. Through this partnership, the clinician can help the family/patient access and coordinate specialty care, educational services, out-of-home care, family support, and other public and private community services that are important to the overall health and well-being of the child/youth/ adult and family.

The model will include the following areas of expertise and support; medical, psychological, economic, social, educational and emergency. All of these systems require funding. Currently, these funding streams are poorly coordinated, inefficient and wasteful such that the resources do not end up where they can best be utilized. One way of addressing this fundamental part of the model would be to have all funds for individuals with a disability be funneled into one large agency (consisting of both public and private stake holders) which would include all of the participants in the individuals care where the identification of needs would be made, the costs assessed and the services provided. There would be no "battle" as to who pays or who is responsible as the funds would come to an impartial multidisciplinary group of experts that would, by consensus, come to decisions about the apportionment of the funds and then monitor the use of these resources with periodic progress reports and reviews. 
Components of the Model:

1. Medical supports: these would include primary care (medical home) and subspecialty care. The individual would have access to appropriate diagnosis and attention to medical issues, would have ongoing primary and preventive care and would have access to care which would be integrated with communication between the medical providers and with the family who would participate in decision making. In addition, the medical system also serves as an educational resource in helping to protect families from being victimized by those offering fast, untried, expensive interventions as a means of "curing" their family member.

2. Psychological supports: This area of expertise would be part of the diagnostic process and treatment of the individual with a disability identifying strengths and weakness. In addition, the behavioral scientist would be available to the family to address psychological stresses, crises and provide therapeutic interventions when indicated.

3. Economic supports: Most families with a disabled member are financially stressed and often have difficulty meeting financial commitments. As part of the support for families, supports for adequate housing, medication, food, therapies, transportation would be provided to the extent they are needed taking into consideration the family's financial and social circumstances. This should not be an "add on" but an integral part of the overall plan for the care of the individual with a disability.

4. Social supports: As has been well-documented IwDs and their families are often marginalized and isolated. They are perceived as being a drain on societal resources and less worthy of society's attention. This, in and of itself, is psychologically stressful. As part of the "dream sheet" this perception of IwDs would be addressed in the form of support for advocacy groups, for political and educational action and a bringing together of all IwDs as a cohesive force rather than the current setting where the developmental disability community is fragmented and is competing with the other for limited resources. Each illness/ condition has its own group and does not link with other groups who have very similar needs. There perhaps should not be a Down syndrome or fragile X syndrome or autism day, but a day for all individuals with disabilities who are united in achieving an equal place in their community and are supported in speaking out for themselves. In addition, there are the more informal groups of parents, and providers, who may come together just to support and listen to each other.

5. Education: The educational community needs to be linked to these other resources. A significant part of a child's life is spent in educational endeavors. This is also true for young adults. Education does not exist in a vacuum. It is influenced by the medical, social and psychological circumstances of the IwDs and has an important impact on her/his well-being. Communication between the medical and educational arenas is critical although they have somewhat different service mandates and skills.

6. Emergency supports: IwDs are more vulnerable to emergencies and mishaps. It would be important and protective, as part of the larger individual plan, to include emergency services, probably those located in the community. There is anecdotal evidence suggesting that if the police and fire departments are aware of an individual with a disability in the community they get to know the family, are not intimidated by the individual and understand her/his challenges and so are able to reach out be more responsive in a crisis. Families have reported that this scenario is very reassuring for them and they feel much safer.

I would suggest that central to the success of this model is that the components be integrated and be seen as part of a larger plan not a piecemeal approach to a challenging problem. In addition, I would argue that if a paradigm shift of the perception of IwDs can be initiated and there is buy-in at the political, governmental, educational, medical and social levels than what may emerge is that the care of IwDs is of value and should be an entitlement and not a privilege for the more affluent.

The debate about disability, family and society is an old one. The needs of individuals with disabilities have not been a particularly high priority in the overall scheme of most societies. However, this population is increasing with the advances in our medical technology and we can no longer ignore them. The manner in which we have addressed the needs of this population has not been successful. Overall care, from diagnosis to treatment and integration into society has been fragmented and disorganized. Thus, new thinking about IwDs has to take place and new models for systems to meet their needs must be developed. A series of ideas has been presented in this article for this edition of the journal. As Asperger noted over 80 years ago, these individuals have much to contribute to our society, given the opportunity to do so. 


\section{References}

1. Resnick MD. The social construction of disability. In: Blum RW, editor. Chronic Illness in Childhood and Adolescence. Orlando: Grune and Stratton; 1984. p. 29-46.

2. Westcott HL, Jones DPH. Annotation: The abuse of disabled children. J Child Psychol Psychiat 1999; 40(4): 497-506.

3. Goldson E. Autism Update: 2016. In: Kappy MS, Barton LL, Berkowitz CD, Carver J, Ziegler M, editors. Advances in Pediatrics. Philadelphia: Elsevier; 2016. p. 333-355. (Vol. 63)

4. American Academy of Pediatrics (AAP). AAP Medical Home policy statement. Pediatrics 2002; 110(1):184186.

Artigo apresentado em 20/08/2016 Aprovado em 25/08/2016

Versão final apresentada em 27/08/2016 
